\title{
Predicting outcome after childhood brain injury
}

\author{
Rob Forsyth BM BCh PhD, Fenella Kirkham MB BChir MD
}

A cquired brain injury is the leading cause of death and neurologic disability in children after infancy. The term refers to a brain injury sustained after a period of normal development, in contrast to cerebral palsy, which denotes injury sustained in very early life. However, operational definitions of the boundaries between these constructs vary internationally. As with cerebral palsy, acquired brain injury encompasses heterogeneous mechanisms of injury. Common mechanisms for acquired brain injury include trauma (e.g., traffic accidents, inflicted injuries, falls), infection (e.g., meningitis, encephalitis), stroke and tumours. Despite this heterogeneity, the usefulness of the concept of acquired brain injury is primarily operational: children with these injuries have similar needs.

Survival with substantial disability after acquired brain injury in childhood has traditionally been seen as uncommon; however, with increasing survival in pediatric intensive care units (ICUs) and better recognition of patterns of postinjury morbidity, this is no longer the case. This change has implications for systems of support for additional physical or learning needs that have evolved around the historically larger group of children with congenital disabilities. ${ }^{1}$

Estimating morbidity rates is particularly challenging for traumatic brain injury - the most common form of acquired brain injury - because injury-independent factors are important determinants of outcome, particularly after mild-tomoderate injuries. Stanley and colleagues ${ }^{2}$ estimate that $6 \%$ of all initial admissions to hospital for traumatic brain injury result in discharge from the acute centre to a rehabilitation facility, providing a very conservative minimum estimate of postinjury rates of morbidity. Adding estimates for nontraumatic acquired brain injuries (including infection and hypoxia-ischemia), ${ }^{3}$ stroke ${ }^{4}$ and brain tumours ${ }^{5}$ suggest that about 1300 children in the United Kingdom (population about 60 million) acquire major neurologic morbidity as the result of acquired brain injury each year, equivalent to the all-severity incidence of cerebral palsy. ${ }^{6}$ Although this figure is only about $1 \%$ of the incidence of adult stroke, the impact of the disability is compounded over many years' future survival. ${ }^{7}$
The need to describe and predict outcomes after acquired brain injuries has daily relevance to practice in the pediatric ICU, where physicians must counsel families and tailor treatments to the severity and perceived prognosis in each situation, including the possibility of withdrawing care. Unfortunately, there are very few systematic reviews and well-conducted randomized controlled trials to support decision-making in these situations. Most of the observations in this review are supported by cohort studies, but heterogeneity of injury type, severity and patient characteristics remain a major challenge. A summary of our literature review is available in Box 1. Outcomes and treatment of hypoxicischemic encephalopathy in newborns is outside the scope of this review.

\section{What factors determine outcome after acquired brain injury?}

The past two decades have seen great advances in our understanding of the pathophysiology of various forms of brain injury. Interest has mainly focused on the cascade of events triggered by the primary injury. These downstream processes cause secondary injuries by a variety of mechanisms including inflammation, the release of toxic free radicals as a result of cell membrane peroxidation and excitotoxicity. Excitotoxicity relates to the sequence of events whereby the depletion of adenosine triphosphate affects the normal reuptake and clearance of excitatory neurotransmitters (particularly glutamate) from the synaptic cleft. The consequent overactivation of
Competing interests: None declared.

This article has been peer reviewed.

Correspondence to: Rob Forsyth, rob.forsyth @ newcastle.ac.uk

CMAJ 2012. DOI:10.1503 /cmaj.111045

\section{KEY POINTS}

- Outcomes after pediatric brain injuries are highly variable, and genetic determinants of response to injury may contribute to this variability.

- In the immature brain, there is a complex interaction between recovery from injury and ongoing development.

- Sophisticated neuroimaging and neurophysiological and biochemical techniques can act as biomarkers that help determine the severity of injuries and predict outcomes, but the use of these techniques has not been validated for children.

- Relatively good motor outcomes may obscure cognitive and behavioural problems, worsening the child's quality of life and that of his or her family. 
postsynaptic glutamate receptors triggers a complex chain of intracellular events resulting in apoptosis (cell death). ${ }^{8}$ In principle, because these events occur in the hours and days after an injury, they would be targets for therapy. ${ }^{8}$ However, optimism that neuroprotective interventions targeting a small number of shared pathophysiologies of secondary injuries would have widespread benefit has proven misplaced, ${ }^{9}$ as shown in systematic reviews of stroke $e^{10,11}$ and traumatic brain injury in adults. ${ }^{12-14}$ Heterogeneities (of injury type, severity and mechanism, and patient characteristics) appear to be more important than previously assumed..$^{15}$

An improved understanding of the biology of the injured brain is vital to improving outcomes after acquired brain injuries. The biology of relearning after injury is essentially the same as that of developmental learning. ${ }^{16}$ Data from studies in animals suggest the neurochemical milieu of the injured brain reverts to a more "immature" pattern ${ }^{16}$ that facilitates plasticity: synaptic connections become more fluid and modifiable. Such plasticity is not necessarily adaptive. The development of epilepsy after injury is an example of the creation of new but maladaptive neural networks. Adaptive recovery occurs through Hebbian relearning (strengthening new synaptic connections with attempted action or practise) in the remaining neural network. Thus, there is an important interplay between the state of development at the time of injury, mechanisms of recovery after injury and ongoing development. We will consider ways in which the cause of injury, age at injury and ongoing rehabilitation determine outcome.

There is no single best approach to describing outcome after acquired brain injury during childhood, ${ }^{17}$ and the one chosen must be appropriate to the purpose at hand (e.g., identifying individual, population, global or domain-specific outcomes). Several instruments have been validated for the description of global outcomes on a population basis (e.g., comparisons between centres or trials). ${ }^{18,19}$ However, their intended uses typically require that as wide a range of outcomes as

\section{Box 1: Evidence used in this review}

We searched the Medline database (1966 to present) for the following terms: "prediction," "outcome," "children," "head trauma," "brain injury" and "coma." We restricted the results to English-language papers. We report the results of published systematic reviews where relevant and available. Other parts of this review are supported by cohort studies, as indicated. Patient heterogeneity remains the major challenge to progress in this area of research, and the most useful cohort studies are those that characterize patients in detail and relate outcome to these characteristics. We indicate where evidence is being extrapolated to the pediatric setting from adult data. possible are captured on a simple scale (Figure 1). ${ }^{18,20}$ Such instruments are poorly suited to detecting responses to therapy on an individual basis. Global outcome descriptors such as the Glasgow Outcome Score ${ }^{20}$ and King's Outcome Scale for Childhood Head Injury (KOSCHI) ${ }^{18}$ have very general categories with levels distinguished by different health constructs. For example, "severe disability" is distinguished from "vegetative state" by evidence of command-following; "moderate disability" outcomes are defined in terms of performance in activities of daily living (e.g., dressing, eating) and gross motor function (standing, walking). Among the best outcomes, independence in activities of daily living will be the norm, but capacities such as executive function (the ability to self-organize and self-direct) will be important discriminators between patients with no deficits and those with mild disability. Thus, a gross motor function measure may be an appropriate evaluation tool for an acute rehabilitation intervention, but would be insensitive to the effects of an intervention aimed at improving social integration late after injury.

More sensitive, domain-specific instruments that have been validated for use in pediatric acquired brain injuries include measures of gross motor function, ${ }^{21}$ functional independence, ${ }^{22,23}$ health-related quality of life ${ }^{24}$ and neuropsychological function. ${ }^{25}$ Recent consensus statements ${ }^{26}$ have suggested standardized "core data elements" that should be captured by all rehabilitation researchers to allow the comparison and aggregation of rehabilitation outcomes.

\section{Do predictors of mortality also predict morbidity?}

Predicting outcome is easier on a population basis than in individual cases, and predicting mortality is simpler than predicting morbidity. Thus, the Medical Research Council of the UK's Corticosteroid Randomisation after Significant Head Injury (CRASH) trial showed a simple loglinear relationship between early scores on the Glasgow Coma Scale and death at 14 days, with an increase of about 10-fold in the risk of death for every 3-point reduction in score. ${ }^{27}$ However, the trial's corresponding morbidity prediction model is much more complex and less powerful. ${ }^{28}$

The central tenet of managing all forms of severe brain injury in the pediatric ICU remains the prevention of additional ischemic events resulting from initial localized brain edema causing increased intracranial pressure, reduced cerebral perfusion, ischemia and further edema. 
Cohort studies confirm that intracranial and cerebral perfusion pressure predict unfavourable outcomes (death or severe disability) in children, ${ }^{29}$ and the potential value of invasive measurement of whole-brain oxygen extraction and anaerobic metabolism ${ }^{30}$ as indicators of adequate brain perfusion. It is important to recognize, however, that some mechanisms of brain injury with important implications for long-term morbidity are not typically associated with marked cerebral edema in the acute phase. The most important example is diffuse axonal injury arising from trauma involving shearing or rotational mechanical forces. The late outcomes for children with such injuries are typically poorly predicted by early indices that predominantly reflect cerebral edema and risk of death.

\section{Does the cause of injury affect the outcome?}

The cause of an injury is a strong determinant of outcome; consequently, most of the literature concerning outcome prediction is etiology-specific.

\section{Traumatic brain injury}

The early recoveries seen after traumatic brain injury can be striking but difficult to predict. A multivariate model of demographic, clinical, radiologic and other predictors developed using data from a large adult cohor $\mathrm{t}^{28}$ had a cumulative $R^{2}$ (i.e., percentage of total variance accounted for) of only $35 \%$. Clinical severity indices (the motor component of the Glasgow Coma Scale and pupil reactivity) were of the highest value. A number of studies involving children have confirmed the prognostic value of various combined clinical scores including motor and pupillary responses $;{ }^{31}$ however, it is clear that much individual variability remains unexplained.

One alternative approach is to use indices that reflect the early rate of recovery as proxies for injury severity. Although somewhat tautological, the number of days taken to reach particular recovery milestones is of considerable pragmatic value as an indicator of severity. McDonald and colleagues validated a pediatric measure of the return of orientation to time, place and person (i.e., the duration of post-traumatic amnesia). ${ }^{32}$ Another study showed that each day's delay in re-establishing basic command-following predicted a 0.6-point reduction in the functional independence measure for children (WeeFIM) for ultimate recovery, and a two-day delay in achieving $50 \%$ of that recovery. ${ }^{33}$

An important cohort study involving children in a vegetative state on day 30 confirmed a much better prognosis for traumatic injuries than for those caused by hypoxia-ischemia. ${ }^{34}$ Our inability to identify individual children making betterthan-expected (or worse) recoveries greatly complicates research in this area. ${ }^{35}$

Motor recoveries after traumatic brain injury can be good, but can lead one to underestimate or not recognize late psychological and psychiatric morbidity, resulting in the re-examination of mild traumatic brain injury in children. Mild injuries are extremely common, and although some are trivial, there is great pragmatic importance in defining severity thresholds below which one can be reasonably confident that late consequences will not occur. Previous literature on this topic had been relatively reassuring. Asarnow and colleagues used a case-control design involving noninjured controls and controls with other (orthopedic) injuries to show that children with traumatic brain injuries sufficient to cause loss of consciousness for up to one hour showed no greater levels of behavioural morbidity than children with other types of injury ${ }^{36}$ This finding has been interpreted as suggesting that the increased behavioural morbidity reported by parents after mild traumatic brain injury may reflect nonspecific emotional reactions to the shock of injury and admission to hospital, or

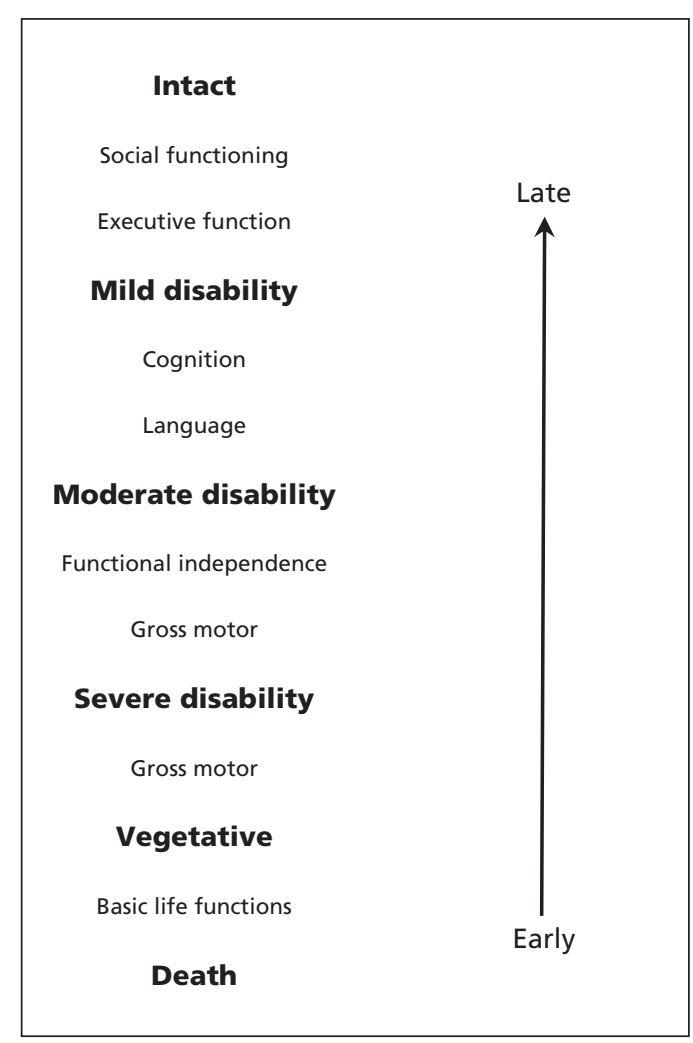

Figure 1: Relationships of health constructs to stages of recovery in the design and selection of outcome measures $^{18,20}$ and the order in which abilities return after injury (arrow). 
may have been present premorbidly and conferred increased risk of injury. ${ }^{37}$ However, a recent prospective national birth cohort study suggests that behavioural morbidity may follow milder traumatic brain injuries in young children, particularly if the injuries are recurrent ${ }^{38}$

A recent meta-analysis confirmed $60 \%$ prevalence of previous substantial traumatic brain injury among adult offenders. ${ }^{39}$ However, issues of causality are complex. Accidental injury sustained through misadventure and inflicted injury are both important mechanisms of traumatic brain injury that raise issues of premorbid differences in risk. ${ }^{40}$ Attention-deficit/hyperactivity disorder, impulsivity ${ }^{38,41}$ and socioeconomic deprivation ${ }^{42}$ are overrepresented in populations with traumatic brain injury. Late emotional and behavioural outcomes after traumatic brain injury are modulated by factors independent of the injury and its severity, particularly the social and family milieu to which the child returns. ${ }^{43}$ Nevertheless, psychological morbidity undoubtedly increases after pediatric traumatic brain injury ${ }^{44}$ in characteristic patterns that reflect injuries to the frontal and temporal lobes. ${ }^{45}$

Inflicted (nonaccidental) traumatic brain injury has a particularly poor outcome, reflecting the much higher energy transfer in repeated shaking or shaking-impact injuries. One case series ${ }^{46}$ reports about $30 \%$ mortality in infants admitted to the pediatric ICU with such injuries.

\section{Cardiac arrest}

Cardiac arrest in a previously healthy child is uncommon. ${ }^{47}$ Well-executed cohort studies confirm that out-of-hospital cardiac arrest has a dismal outcome, with $1 \%$ of children surviving to discharge from hospital $(0.3 \%$ of whom are neurologically intact) ${ }^{48}$ Presumed cardiac arrest in infants (i.e., sudden infant death syndrome [SIDS] and "near-miss" SIDS) also has poor outcomes, particularly if seizures occur. ${ }^{49}$

With advances in the care of children with more complex medical conditions, in-hospital cardiac arrest has become an important problem; $;{ }^{50}$ it is more common and survival is better than for cardiac arrest not occurring in hospital. ${ }^{51}$ Research is focusing on the quality of resuscitation care, ${ }^{52}$ and the roles of extracorporeal membrane oxygenation ${ }^{53}$ and therapeutic hypothermia $^{54}$ in further improving outcomes.

\section{Near drowning}

Near drowning requires separate consideration because the outcomes of such events can be remarkably good. Survival after near drowning is as high as $80 \%{ }^{55}$ for people who gasp within 40 minutes of rescue and regain consciousness soon thereafter. Although persistent vegetative state is generally a less common outcome after acquired brain injury in children than in adults, neurologic outcomes after near drowning tend to be bimodal: $: 55$ either vegetative (10\% of survivors) or largely intact $(84 \%)$. The latter group consists predominantly of children who were not in a coma on admission to hospital, and who had reactive pupils, normal $\mathrm{pH}$ and normoglycemia. Water temperature is an important determinant of outcome; there are isolated case reports of intact survival in icy water even after prolonged immersion. ${ }^{56}$

\section{Bacterial meningitis}

A recent systematic review of prognostic models in pediatric bacterial meningitis identified delayed presentation, reduced consciousness, prolonged seizures, young age and male sex among other adverse risk factors. ${ }^{57}$ Pneumococcal meningitis had a particularly poor outcome. ${ }^{57}$

\section{Other causes}

Beyond broad statements on prognosis for specific causes of injury as described previously, the challenge of outcome prediction in individual cases becomes clearer. The outcome for many encephalopathies, including trauma and meningitis, may be determined by a combination of the severity of the primary injury, including the degree of damage to white matter; ${ }^{58,59}$ the contribution of secondary factors, such as venous ${ }^{60}$ and arterial focal ischemia, ${ }^{61}$ the onset of status epilepticus ${ }^{62}$ and the development of intracranial hypertension; ${ }^{63}$ and multiple genetic determinants of the response to injury. ${ }^{64,65}$

\section{What effect does age at injury have on outcome?}

The discussion so far has failed to incorporate the defining feature of pediatric acquired brain injury; namely that the injury happens to an immature nervous system that must complete its development in an injured state. Injury interacts with the ontogeny of the brain system(s) affected. For example, at birth, there are contralateral and ipsilateral projections of the corticospinal tract to the spinal $\alpha$ motor neurons ${ }^{66}$ Normally, the ipsilateral projections are lost through competitive inhibition during the first year or two after birth. However, extensive unihemispheric injury before this change occurs may result in the preservation of uncrossed projections from intact cortex that would otherwise have regressed (Appendix 1, available at www.cmaj.ca /lookup/suppl/doi:10.1503/cmaj.111045/-/DC1). ${ }^{1}$

The literature addressing the interplay between early injury to the brain and its subsequent 
development is complex.$^{67}$ The very young brain can appear remarkably resilient to focal injury, ${ }^{68}$ although this view has been challenged ${ }^{69}$ Injury in the very young brain may be mitigated by redirection or reallocation of incompletely committed long-range projections - for example, allowing the language cortex to relocate to the contralateral hemisphere - but such processes are not universal, and some brain areas seem more adaptable than others. ${ }^{70,71}$

Interpreting the empiric clinical literature is complicated by the difficulty of studying age at injury in isolation from confounding agedependent differences in the cause of injury (and thus the size and location of the lesion) and the presence of comorbid epilepsy. ${ }^{72}$ What is clear, however, is that widespread views that young brains make better recoveries are naive. ${ }^{73}$ Early injury alters the entire developmental trajectory (the challenge of making "a year's progress every year" with an injured brain), and effects can compound through childhood. This is particularly clear in the literature surrounding pediatric traumatic brain injury ${ }^{74}$ where sometimes impressive early motor recoveries obscure the characteristic emergence of cognitive and psychological morbidity in subsequent years. ${ }^{75}$ The complex way in which initially "latent" morbidity may emerge can result in nonattribution of late effects to the early traumatic brain injury.'

\section{What investigations may help predict outcome?}

Attempts to improve prognostication have focused on increasingly detailed characterization of the injury - for example, using more sophisticated neurophysiological and neuroradiological modalities to distinguish different pathologies and more precisely quantify subtle injury. ${ }^{76,77}$

Associations between outcome and levels of serum-based biomarkers of brain injury have been reported in pediatric cohort studies. Biomarkers include neuron-specific enolase, ${ }^{78}$ $\mathrm{S}_{100 \mathrm{~b}^{79}}$ and glial fibrillary acid protein. ${ }^{80} \mathrm{Al}$ though associations between increased levels of biomarkers and poorer outcomes may be statistically significant, the specificity and sensitivity of isolated measurements are low. More sophisticated analyses of temporal profiles of biomarkers, ${ }^{81}$ multiple profiles of biomarkers ${ }^{82}$ and biomarker profiles in combination with clinical data ${ }^{83}$ have been proposed.

Neurophysiological biomarkers of brain function soon after injury that predict outcome have also been developed, although most of them are research tools and are not in widespread clinical use. In addition, many measures have not been specifically studied for use in children. Certain findings in conventional electroencephalography (EEG), such as burst suppression and $\alpha$ coma, ${ }^{84}$ are recognized as indicators of major disruption in brain function; however, these signs are nonspecific and cannot distinguish the effects of injury from other causes of dysfunction (e.g., anesthesia). Although there are relatively few data from studies using continuous monitoring with EEG, the presence of electrographic seizures appears to predict poor prognosis. ${ }^{85}$ More sophisticated analyses of EEG ${ }^{86}$ correlate with outcome; however, their independent predictive value (i.e., the extent to which they elaborate on what is clinically apparent) and the appropriate confidence limits on such predictions - particularly for children - remain to be established.

Evoked potentials may have more value. The persistent absence of somatosensory evoked potentials is specific for a poor outcome after acquired brain injury in adults, ${ }^{87}$ although care must be taken to exclude the presence of subdural hemorrhages or severe selective brainstem injury that might attenuate or prevent the transmission of a sensory stimulus to a mostly intact cortex. Such findings can form part of the basis for the decision to withdraw care in adults, but they have not been specifically validated in children. ${ }^{88}$

Conventional short-latency auditory evoked potentials reflect brainstem function and thus correlate with mortality rather than morbidity. ${ }^{89}$ However, the preservation of certain late auditory evoked potentials that reflect cortical auditory processing may provide useful confirmation of a relatively good prognosis..$^{90}$ The absence of these evoked potentials is not informative, as they are relatively sensitive to anesthesia. Longlatency auditory evoked potentials are present even in newborns, ${ }^{91}$ although their prognostic value in younger children remains to be established. As with all neurophysiological tests, trends over time and considering both neurophysiological and clinical data ${ }^{92}$ may be particularly informative.

\section{Does rehabilitation improve outcome?}

Defining the nature of effective interventions in adult stroke has been helped by large numbers, the ability to define severity bands and relative homogeneity in the types and locations of injuries. ${ }^{93}$ The effectiveness of adult stroke units $^{94}$ has allowed the examination of their es- 
sential attributes. ${ }^{95}$ Comparable evidence for the effectiveness of acute intensive rehabilitation for adults after traumatic brain injury is starting to emerge. ${ }^{96}$

By comparison, there is currently only limited evidence for the efficacy of rehabilitation in pediatric acquired brain injury. The existing evidence for the efficacy of cognitive rehabilitation (aimed at the remediation of executive and attentional deficits) has been reviewed by Slomine and Locascio. ${ }^{97}$ Whether the benefits of such interventions generalize to functions beyond the specific trait targeted is still to be established. Epidemiological studies emphasize that more "distal" outcomes (both in terms of time and the more indirect effects of injury on the ability of the child and his or her family to participate in life) are predicted more strongly by factors independent of the injury itself, such as family function and coping styles. ${ }^{43}$ Of the few randomized controlled trials in this area, two provide evidence for the efficacy of family empowerment. ${ }^{98,99}$ It is likely that interventions tailored to supporting the child and his or her family in the context in which they live will be the most effective. ${ }^{100}$

Appendix 2 (available at www.cmaj.ca/lookup /suppl/doi:10.1503/cmaj.111045/-/DC1) provides a fictional example of how to use the results of this review in clinical practice. Additional resources for clinicians, patients and families are presented in Appendix 3 (available at www.cmaj.ca/lookup /suppl/doi:10.1503/cmaj.111045/-/DC1).

\section{Unanswered questions}

The evidence base concerning outcome after acquired brain injury in children is poor. Despite reasonably robust evidence for outcomes in adults, the distinctive neurobiology of the developing brain limits its applicability in children without separate validation for that population.

Improving outcomes for children with acquired brain injuries poses challenges at multiple levels. Primary prevention remains vital, particularly for injuries resulting from accidental trauma and infections. The failure of generic neuroprotective measures suggests that secondary prevention strategies should be tailored to specific causes and severities of injury. Approaches to tertiary prevention (e.g., rehabilitation to minimize the effects of established neurologic morbidity; addressing educational, psychological and other effects) are probably best addressed generically; what children with acquired brain injuries have in common is greater than what distinguishes them, and the inefficiencies of research confined to etiologyspecific "silos" should be avoided.

\section{References}

1. Forsyth RJ. Back to the future: rehabilitation of children after brain injury. Arch Dis Child 2010;95:554-9.

2. Stanley RM, Bonsu BK, Zhao W, et al. US estimates of hospitalized children with severe traumatic brain injury: implications for clinical trials. Pediatrics 2012;129:e24-30.

3. Forsyth RJ, Wong CP, Kelly TP, et al. Cognitive and adaptive outcomes and age at insult effects after non-traumatic coma. Arch Dis Child 2001;84:200-4.

4. de Veber G. The epidemiology of childhood stroke. Stroke and cerebrovascular disease in childhood. London (UK): MacKeith Press (International Reviews in Child Neurology); 2010. p. 22-6.

5. Boman KK, Lindblad F, Hjern A. Long-term outcomes of childhood cancer survivors in Sweden: a population-based study of education, employment, and income. Cancer 2010;116:1385-91.

6. Odding E, Roebroeck ME, Stam HJ. The epidemiology of cerebral palsy: incidence, impairments and risk factors. Disabil Rehabil 2006;28:183-91.

7. Strauss DJ, Shavelle RM, Anderson TW. Long-term survival of children and adolescents after traumatic brain injury. Arch Phys Med Rehabil 1998;79:1095-100.

8. Kochanek PM, Clark RSB, Ruppel RA, et al. Biochemical, cellular, and molecular mechanisms in the evolution of secondary damage after severe traumatic brain injury in infants and children: lessons learned from the bedside. Pediatr Crit Care Med 2000; 1:4-19.

9. Beauchamp K, Mutlak H, Smith WR, et al. Pharmacology of traumatic brain injury: Where is the "golden bullet"? Mol Med 2008; 14:731-40.

10. Den Hertog HM, van der Worp HB, Tseng MC, et al. Cooling therapy for acute stroke. Cochrane Database of Syst Rev 2009; (1):CD001247.

11. Qizilbash N, Lewington S. Corticosteroids for acute ischaemic stroke. Cochrane Database of Syst Rev 2002;(2):CD000064.

12. Alderson P, Roberts I. Corticosteroids for acute traumatic brain injury. Cochrane Database of Syst Rev 2005;(1):CD000196.

13. Willis C, Lybrand S. Excitatory amino acid inhibitors for traumatic brain injury. Cochrane Database of Syst Rev 2003;(1): CD003986.

14. Sydenham E, Roberts I. Hypothermia for traumatic head injury. Cochrane Database of Syst Rev 2009;(2):CD001048.

15. Saatman KE, Duhaime A-C, Bullock R, et al. Classification of traumatic brain injury for targeted therapies. $J$ Neurotrauma 2008;25:719-38

16. Cramer SC, Chopp M. Recovery recapitulates ontogeny. Trends Neurosci 2000;23:265-71.

17. Forsyth R. Describing outcome after acquired brain injury: ending the quest for the holy grail. Dev Med Child Neurol 2008;50:405.

18. Crouchman M, Rossiter L, Colaco T, et al. A practical outcome scale for paediatric head injury. Arch Dis Child 2001;84:120-4.

19. Fiser DH. Assessing the outcome of pediatric intensive care. $J$ Pediatr 1992;121:68-74.

20. Levin HS, Boake C, Song J, et al. Validity and sensitivity to change of the Extended Glasgow Outcome Scale in mild to moderate traumatic brain injury. J Neurotrauma 2001;18:575-84.

21. Linder-Lucht $\mathrm{M}$, Othmer V, Walther $\mathrm{M}$, et al. Validation of the Gross Motor Function Measure for use in children and adolescents with traumatic brain injuries. Pediatrics 2007;120:e880-6.

22. Rice SA, Blackman J, Braun S, et al. Rehabilitation of children with traumatic brain injury: descriptive analysis of a nationwide sample using the WeeFIM. Arch Phys Med Rehabil 2005;86:834-6.

23. Vasa RA, Grados M, Slomine B, et al. Neuroimaging correlates of anxiety after pediatric traumatic brain injury. Biol Psychiatry 2004;55:208-16.

24. McCarthy ML, MacKenzie EJ, Durbin DR, et al. The Pediatric Quality of Life Inventory: an evaluation of its reliability and validity for children with traumatic brain injury. Arch Phys Med Rehabil 2005;86:1901-9.

25. Slomine BS, Salorio CF, Grados MA, et al. Differences in attention, executive functioning, and memory in children with and without ADHD after severe traumatic brain injury. J Int Neuropsychol Soc 2005;11:645-53.

26. McCauley SR, Wilde EA, Anderson VA, et al. Recommendations for the use of common outcome measures in pediatric traumatic brain injury research. J Neurotrauma 2012;29:678-705.

27. Perel P, Arango M, Clayton T, et al. Predicting outcome after traumatic brain injury: practical prognostic models based on large cohort of international patients. BMJ 2008;336:425-9.

28. Lingsma HF, Roozenbeek B, Steyerberg EW, et al. Early prognosis in traumatic brain injury: from prophecies to predictions. Lancet Neurol 2010;9:543-54.

29. Carter BG, Butt W, Taylor A. ICP and CPP: excellent predictors of long term outcome in severely brain injured children. Childs Nerv Syst 2008;24:245-51. 
30. Alten J, Mariscalco MM. Critical appraisal of Perez et al.: jugular venous oxygen saturation or arteriovenous difference of lactate content and outcome in children with severe traumatic brain injury. Pediatr Crit Care Med 2005;6:480-2.

31. Cassidy LD, Potoka DA, Adelson PD, et al. Development of a novel method to predict disability after head trauma in children. J Pediatr Surg 2003;38:482-5.

32. McDonald CM, Jaffe KM, Fay GC, et al. Comparison of indices of traumatic brain injury severity as predictors of neurobehaviora outcome in children. Arch Phys Med Rehabil 1994;75:328-37.

33. Forsyth RJ, Salorio CF, Christensen JR. Modelling early recovery patterns after paediatric traumatic brain injury. Arch Dis Child 2010;95:266-70.

34. Heindl UT, Laub MC. Outcome of persistent vegetative state following hypoxic or traumatic brain injury in children and adolescents. Neuropediatrics 1996;27:94-100.

35. Forsyth R. Efficient translational rehabilitation randomised controlled trial designs using disease progress modelling and trial simulation. Neuropsychol Rehabil 2009;19:891-903.

36. Asarnow RF, Satz P, Light R, et al. The UCLA study of mild closed head injury in children and adolescents. Oxford (UK): Oxford University Press; 1995.

37. McKinlay A. Controversies and outcomes associated with mild traumatic brain injury in childhood and adolescences. Child Care Health Dev 2010;36:3-21.

38. Mckinlay A, Grace RC, Horwood LJ, et al. Long-term behavioural outcomes of pre-school mild traumatic brain injury. Child Care Health Dev 2010;36:22-30.

39. Shiroma EJ, Ferguson PL, Pickelsimer EE. Prevalence of traumatic brain injury in an offender population: a meta-analysis. $J$ Correct Health Care 2010;16:147-59.

40. Demellweek C, Baldwin T, Appleton R, et al. A prospective study and review of pre-morbid characteristics in children with traumatic brain injury. Pediatr Rehabil 2002;5:81-9.

41. Gerring JP, Brady KD, Chen A, et al. Premorbid prevalence of ADHD and development of secondary ADHD after closed head injury. J Am Acad Child Adolesc Psychiatry 1998;37:647-54.

42. Parslow RC, Morris KP, Tasker RC, et al.; UK Paediatric Traumatic Brain Injury Study Steering Group, et al. Epidemiology of traumatic brain injury in children receiving intensive care in the UK. Arch Dis Child 2005;90:1182-7.

43. Yeates KO, Taylor HG, Drotar D, et al. Preinjury family environment as a determinant of recovery from traumatic brain injuries in school-age children. J Int Neuropsychol Soc 1997;3: 617-30.

44. Brown G, Chadwick O, Shaffer D, et al. A prospective study of children with head injuries: III. Psychiatric sequelae. Psychol Med 1981;11:63-78.

45. Levin HS, Zhang L, Dennis M, et al. Psychosocial outcome of TBI in children with unilateral frontal lesions. J Int Neuropsychol Soc 2004;10:305-16.

46. Scavarda D, Gabaudan C, Ughetto F, et al. Initial predictive factors of outcome in severe non-accidental head trauma in children. Childs Nerv Syst 2010;26:1555-61.

47. Park CB, Shin SD, Suh GJ, et al. Pediatric out-of-hospital cardiac arrest in Korea: a nationwide population-based study. Resuscitation 2010;81:512-7.

48. Donoghue AJ, Nadkarni V, Berg RA, et al. Out-of-hospital pediatric cardiac arrest: an epidemiologic review and assessment of current knowledge. Ann Emerg Med 2005;46:512-22.

49. Constantinou JE, Gillis J, Ouvrier RA, et al. Hypoxic-ischaemic encephalopathy after near miss sudden infant death syndrome. Arch Dis Child 1989;64:703-8.

50. Moler FW, Donaldson AE, Meert K, et al. Multicenter cohort study of out-of-hospital pediatric cardiac arrest. Crit Care Med 2011; 39:141-9.

51. Meaney PA, Nadkarni VM, Cook EF, et al. Higher survival rates among younger patients after pediatric intensive care unit cardiac arrests. Pediatrics 2006;118:2424-33.

52. Donoghue AJ, Nadkarni VM, Elliott M, et al.; American Heart Assocation National Registry of Cardiopulmonary Resuscitation Investigators. Effect of hospital characteristics on outcomes from pediatric cardiopulmonary resuscitation: a report from the national registry of cardiopulmonary resuscitation. Pediatrics 2006;118:995-1001.

53. Prodhan P, Fiser RT, Dyamenahalli U, et al. Outcomes after extracorporeal cardiopulmonary resuscitation (ECPR) following refractory pediatric cardiac arrest in the intensive care unit. Resuscitation 2009;80:1124-9.

54. Doherty DR, Parshuram CS, Gaboury I, et al. Hypothermia therapy after pediatric cardiac arrest. Circulation 2009;119:1492-500.

55. Graf WD, Cummings P, Quan L, et al. Predicting outcome in pediatric submersion victims. Ann Emerg Med 1995;26:312-9.

56. Schmidt U, Fritz KW, Kasperczyk W, et al. Successful resuscita- tion of a child with severe hypothermia after cardiac arrest of 88 minutes. Prehosp Disaster Med 1995;10:60-2.

57. de Jonge RCJ, van Furth AM, Wassenaar M, et al. Predicting sequelae and death after bacterial meningitis in childhood: a systematic review of prognostic studies. BMC Infect Dis 2010;10:232.

58. Tasker RC, Westland AG, White DK, et al. Corpus callosum and inferior forebrain white matter microstructure are related to functional outcome from raised intracranial pressure in child traumatic brain injury. Dev Neurosci 2010;32:374-84.

59. Galloway NR, Tong KA, Ashwal S, et al. Diffusion-weighted imaging improves outcome prediction in pediatric traumatic brain injury. J Neurotrauma 2008;25:1153-62.

60. Sébire G, Tabarki B, Saunders DE, et al. Cerebral venous sinus thrombosis in children: risk factors, presentation, diagnosis and outcome. Brain 2005;128:477-89.

61. Kalita J, Misra UK, Nair PP. Predictors of stroke and its significance in the outcome of tuberculous meningitis. J Stroke Cerebrovasc Dis 2009;18:251-8.

62. Vespa PM, McArthur DL, Xu Y, et al. Nonconvulsive seizures after traumatic brain injury are associated with hippocampal atrophy. Neurology 2010;75:792-8.

63. Slawik H, Salmond CH, Taylor-Tavares JV, et al. Frontal cerebral vulnerability and executive deficits from raised intracranial pressure in child traumatic brain injury. J Neurotrauma 2009;26: $1891-903$.

64. Waters RJ, Nicoll JAR. Genetic influences on outcome following acute neurological insults. Curr Opin Crit Care 2005;11: 105-10

65. Jordan BD. Genetic influences on outcome following traumatic brain injury. Neurochem Res 2007;32:905-15.

66. Eyre JA. Corticospinal tract development and its plasticity after perinatal injury. Neurosci Biobehav Rev 2007;31:1136-49.

67. Varier S, Kaiser M, Forsyth R. Establishing, versus maintaining, brain function: a neuro-computational model of cortical reorganization after injury to the immature brain. J Int Neuropsychol Soc 2011;17:1030-8.

68. Stiles J, Reilly J, Paul B, et al. Cognitive development following early brain injury: evidence for neural adaptation. Trends Cogn Sci 2005;9:136-43.

69. Anderson V, Spencer-Smith M, Leventer R, et al. Childhood brain insult: can age at insult help us predict outcome? Brain 2009;132:45-56.

70. Liégeois F, Connelly A, Baldeweg T, et al. Speaking with a single cerebral hemisphere: fMRI language organization after hemispherectomy in childhood. Brain Lang 2008;106:195-203.

71. Juenger H, de Haan B, Krägeloh-Mann I, et al. Early determination of somatosensory cortex in the human brain. Cereb Cortex 2011;21:1827-31.

72. Lidzba K, Wilke M, Staudt M, et al. Early plasticity versus early vulnerability: the problem of heterogeneous lesion types. Brain 2009; 132(Pt 10):e128; author reply: e129.

73. Webb C, Rose FD, Johnson DA, et al. Age and recovery from brain injury: clinical opinions and experimental evidence. Brain Inj 1996;10:303-10.

74. Ewing-Cobbs L, Fletcher JM, Levin HS, et al. Longitudinal neuropsychological outcome in infants and preschoolers with traumatic brain injury. J Int Neuropsychol Soc 1997;3:581-91.

75. Anderson VA, Morse SA, Klug G, et al. Predicting recovery from head injury in young children: a prospective analysis. $J$ Int Neuropsychol Soc 1997;3:568-80.

76. Ashwal S, Holshouser BA, Tong KA. Use of advanced neuroimaging techniques in the evaluation of pediatric traumatic brain injury. Dev Neurosci 2006;28:309-26.

77. Tasker RC, Boyd S, Harden A, et al. Monitoring in non-traumatic coma. Part II: electroencephalography. Arch Dis Child 1988; 63:895-9.

78. Bandyopadhyay S, Hennes H, Gorelick MH, et al. Serum neuron-specific enolase as a predictor of short-term outcome in children with closed traumatic brain injury. Acad Emerg Med 2005; $12: 732-8$.

79. Berger RP, Kochanek PM. Urinary S100B concentrations are increased after brain injury in children: a preliminary study. Pediatr Crit Care Med 2006;7:557-61.

80. Bembea MM, Savage W, Strouse JJ, et al. Glial fibrillary acidic protein as a brain injury biomarker in children undergoing extracorporeal membrane oxygenation. Pediatr Crit Care Med 2011; 12:572-9.

81. Berger RP, Bazaco MC, Wagner AK, et al. Trajectory analysis of serum biomarker concentrations facilitates outcome prediction after pediatric traumatic and hypoxemic brain injury. Dev Neurosci 2010;32:396-405.

82. Lo T-YM, Jones PA, Minns RA. Pediatric brain trauma outcome prediction using paired serum levels of inflammatory mediators and brain-specific proteins. J Neurotrauma 2009;26:1479-87. 
83. Lo T-YM, Jones PA, Minns RA. Combining coma score and serum biomarker levels to predict unfavorable outcome following childhood brain trauma. J Neurotrauma 2010;27:2139-45.

84. Abusleme IE, Chen JWY. Alternative cerebral generators and circuitry pathways in alpha coma revealed by independent component analysis. Clin Neurophysiol 2009;120:686-94.

85. Murdoch-Eaton D, Darowski M, Livingston J. Cerebral function monitoring in paediatric intensive care: useful features for predicting outcome. Dev Med Child Neurol 2001;43:91-6.

86. Nenadovic V, Hutchison JS, Dominguez LG, et al. Fluctuations in cortical synchronization in pediatric traumatic brain injury. $J$ Neurotrauma 2008;25:615-27.

87. Zandbergen EG, de Haan RJ, Stoutenbeek CP, et al. Systematic review of early prediction of poor outcome in anoxic-ischaemic coma. Lancet 1998;352:1808-12.

88. Carrai R, Grippo A, Lori S, et al. Prognostic value of somatosensory evoked potentials in comatose children: a systematic literature review. Intensive Care Med 2010;36:1112-26.

89. Goitein KJ, Amit Y, Fainmesser P, et al. Diagnostic and prognostic value of auditory nerve brainstem evoked responses in comatose children. Crit Care Med 1983;11:91-4.

90. Fischer C, Luauté J, Adeleine P, et al. Predictive value of sensory and cognitive evoked potentials for awakening from coma. $\mathrm{Neu}$ rology 2004;63:669-73.

91. Cheour M, Leppänen PH, Kraus N. Mismatch negativity $(\mathrm{MMN})$ as a tool for investigating auditory discrimination and sensory memory in infants and children. Clin Neurophysiol 2000;111:4-16.

92. Carter BG, Taylor A, Butt W. Severe brain injury in children: long-term outcome and its prediction using somatosensory evoked potentials (SEPs). Intensive Care Med 1999;25:722-8.

93. Langhorne P, Coupar F, Pollock A. Motor recovery after stroke a systematic review. Lancet Neurol 2009;8:741-54.
94. Govan L, Weir CJ, Langhorne P, for the Stroke Unit Trialists Collaboration. Organized inpatient (stroke unit) care for stroke. Stroke 2008 Jun. 12. [Epub ahead of print].

95. Langhorne P, Dey P, Woodman M, et al. Is stroke unit care portable? A systematic review of the clinical trials. Age Ageing 2005;34:324-30.

96. Greenwood R. Acute rehabilitation after severe head injury. $\mathrm{Br} J$ Neurosurg 2004;18:573-5.

97. Slomine B, Locascio G. Cognitive rehabilitation for children with acquired brain injury. Dev Disabil Res Rev 2009;15:133-43.

98. Braga LW, Da Paz Júnior AC, Ylvisaker M. Direct cliniciandelivered versus indirect family-supported rehabilitation of children with traumatic brain injury: a randomized controlled trial. Brain Inj 2005; 19:819-31.

99. Glang A, McLaughlin K, Schroeder S. Using interactive multimedia to teach parent advocacy skills: an exploratory study. $J$ Head Trauma Rehabil 2007;22:198-205.

100. Yeates KO, Bigler ED, Dennis M, et al. Social outcomes in childhood brain disorder: a heuristic integration of social neuroscience and developmental psychology. Psychol Bull 2007;133: 535-56.

Affiliations: From the Institute of Neuroscience (Forsyth), Newcastle University and Great North Children's Hospital, Newcastle-upon-Tyne, UK, and the Institute of Child Health (Kirkham), University College London, London, UK, and University Hospitals (Kirkham), Southampton, UK

Contributors: Both of the authors contributed to the conception and design of the article, conducted the literature review, drafted and revised the manuscript for important intellectual content, and approved the final version submitted for publication. 